\title{
Changes in neurocognitive functioning during transition to manifest disease: comparison of individuals at risk for schizophrenic and bipolar affective psychoses
}

\author{
Metzler, S ; Dvorsky, D ; Wyss, C ; Müller, M ; Gerstenberg, M ; Traber-Walker, N ; Walitza, S ; \\ Theodoridou, A ; Rössler, W ; Heekeren, K
}

\begin{abstract}
BACKGROUND Neurocognitive deficits are important aspects of schizophrenic disorder because they have a strong impact on social and vocational outcomes. Previously it was assumed that cognitive abilities progressively deteriorate with illness onset. However, recent research results have contradicted this with observations of continuous or even improved performance in individuals at risk for psychosis or manifest schizophrenia. The objective of our longitudinal study was to examine neurocognitive functioning in help-seeking individuals meeting basic symptoms or ultra-high-risk criteria for schizophrenic psychosis (HRSchiz) or risk criteria for affective psychosis (HRBip). The progression of cognitive functioning in individuals converting to psychosis was compared with that of at-risk individuals who did not convert during the follow-up period. METHOD Data were available from 86 study participants who completed neurocognitive and clinical assessments at baseline and, on average, 12.8 (s.d. = 1.5) months later. Neurocognitive measures were grouped according to their load in factor analysis to five cognitive domains: speed, attention, fluency, learning and memory, and working memory. RESULTS Neurocognitive functioning in HRSchiz and HRBip individuals generally improved over time. Subjects converting to manifest psychosis displayed a stable neurocognitive profile from baseline to follow-up. Compared with non-converters, they had already demonstrated a significantly lower level of performance during their baseline examinations. CONCLUSIONS Our data provide no evidence for a progressive cognitive decline in individuals at risk of psychosis. In line with the neurodevelopmental model, our findings suggest that cognitive deficits are already present very early, before or during the prodromal stage of the illness.
\end{abstract}

DOI: https://doi.org/10.1017/S0033291715000057

Posted at the Zurich Open Repository and Archive, University of Zurich

ZORA URL: https://doi.org/10.5167/uzh-109857

Journal Article

Published Version

Originally published at:

Metzler, S; Dvorsky, D; Wyss, C; Müller, M; Gerstenberg, M; Traber-Walker, N; Walitza, S; Theodoridou, A; Rössler, W; Heekeren, K (2015). Changes in neurocognitive functioning during transition to manifest disease: comparison of individuals at risk for schizophrenic and bipolar affective psychoses. Psychological Medicine, 45(10):2123-2134.

DOI: https://doi.org/10.1017/S0033291715000057 


\title{
Changes in neurocognitive functioning during transition to manifest disease: comparison of individuals at risk for schizophrenic and bipolar affective psychoses
}

\author{
S. Metzler ${ }^{1 *}$, D. Dvorsky ${ }^{1,2}$, C. Wyss ${ }^{1,2}$, M. Müller ${ }^{1,2}$, M. Gerstenberg ${ }^{1,3}$, N. Traber-Walker ${ }^{1,3}$, \\ S. Walitza ${ }^{3}$, A. Theodoridou ${ }^{1,2}$, W. Rössler ${ }^{1,4,5}$ and K. Heekeren ${ }^{1,2}$ \\ ${ }^{1}$ The Zurich Program for Sustainable Development of Mental Health Services (ZInEP), University Hospital of Psychiatry Zurich, Switzerland \\ ${ }^{2}$ Department of Psychiatry, Psychotherapy and Psychosomatics, University Hospital of Psychiatry Zurich, Switzerland \\ ${ }^{3}$ Department of Child and Adolescent Psychiatry, University of Zurich, Switzerland \\ ${ }^{4}$ Collegium Helveticum, a joint Research Institute between the University of Zurich and the Swiss Federal Institute of Technology Zurich, Switzerland \\ ${ }^{5}$ Institute of Psychiatry, Laboratory of Neuroscience (LIM 27), University of Sao Paulo, Sao Paulo, Brazil
}

\begin{abstract}
Background. Neurocognitive deficits are important aspects of schizophrenic disorder because they have a strong impact on social and vocational outcomes. Previously it was assumed that cognitive abilities progressively deteriorate with illness onset. However, recent research results have contradicted this with observations of continuous or even improved performance in individuals at risk for psychosis or manifest schizophrenia. The objective of our longitudinal study was to examine neurocognitive functioning in help-seeking individuals meeting basic symptoms or ultra-high-risk criteria for schizophrenic psychosis (HRSchiz) or risk criteria for affective psychosis (HRBip). The progression of cognitive functioning in individuals converting to psychosis was compared with that of at-risk individuals who did not convert during the follow-up period.
\end{abstract}

Method. Data were available from 86 study participants who completed neurocognitive and clinical assessments at baseline and, on average, 12.8 (S.D. = 1.5) months later. Neurocognitive measures were grouped according to their load in factor analysis to five cognitive domains: speed, attention, fluency, learning and memory, and working memory.

Results. Neurocognitive functioning in HRSchiz and HRBip individuals generally improved over time. Subjects converting to manifest psychosis displayed a stable neurocognitive profile from baseline to follow-up. Compared with non-converters, they had already demonstrated a significantly lower level of performance during their baseline examinations.

Conclusions. Our data provide no evidence for a progressive cognitive decline in individuals at risk of psychosis. In line with the neurodevelopmental model, our findings suggest that cognitive deficits are already present very early, before or during the prodromal stage of the illness.

Received 23 June 2014; Revised 23 December 2014; Accepted 31 December 2014; First published online 2 February 2015

Key words: Cognition, help-seeking, neuropsychology, prodrome, psychosis/bipolar.

\section{Introduction}

Schizophrenia has long been regarded as a progressive brain disease that leads to severe cognitive and behavioural decline (Jablensky, 2007; Zipursky et al. 2013). Hence, there is a wealth of literature related to cognitive functioning in patients with schizophrenia. On average, these individuals show cognitive deficits at a level approximately 1-2 standard deviations (s.D.) below the mean for healthy individuals (Heinrichs \& Zakzanis, 1998; Michie et al. 2000; Fioravanti et al.

\footnotetext{
* Address for correspondence: S. Metzler, Ph.D., The Zurich Program for Sustainable Development of Mental Health Services (ZInEP), University Hospital of Psychiatry Zurich, Switzerland.

(Email: sibylle.metzler@dgsp.uzh.ch)
}

2005). Brain-imaging studies have confirmed this by demonstrating that alterations in brain structure and presumably function may occur at some point in the transition to full-blown psychosis (Zipursky et al. 1998; Shenton et al. 2001; Pantelis et al. 2003). Researchers have proposed that different neuroregressive processes, such as excessive pruning or inflammation starting in adolescence and early adulthood, are the neurobiological substrate for this cognitive deterioration (Insel, 2010; Bora \& Murray, 2013).

Undoubtedly, a substantial portion of patients with schizophrenia show a chronic course leading to a high degree of disability (van Os \& Kapur, 2009). It has been suggested that after illness onset both patients with schizophrenia and patients with bipolar disorder may exhibit a decline in cognitive function. Thus, a 
meta-analysis revealed widespread general cognitive deficits in both disorders, with quantitative rather than qualitative differences between the diagnostic groups (Stefanopoulou et al. 2009). However, the view that this illness is inevitably progressive may have emerged from a referral and sample bias (Zipursky et al. 2013). That is, research on cognition in schizophrenia may be biased toward those who have been ill repeatedly or for many years (i.e. a prevalence sample) while those who have only brief periods of illness are underrepresented (i.e. an incidence sample) (Cohen \& Cohen, 1984). In addition, findings regarding the progression of cognitive deficits over the course of the disorder may be conversely discussed due to a heightened prevalence rate of confounding variables associated with chronicity, such as other co-morbid psychiatric diagnoses, antipsychotic medication, institutionalization, or poor physical health (Fusar-Poli et al. 2012a). Those variables might equally contribute to a negative course as might the progressive nature of schizophrenia. Some researchers have critically questioned whether schizophrenia is inherently progressive and have suggested that the disability may result - unless referral and sampling biases exist - from stable deficits that are established before the onset of the illness (Becker et al. 2010; Bora \& Murray, 2013; Zipursky et al. 2013). In line with a neurodevelopmental model of schizophrenia, recent studies have provided evidence that cognitive and intellectual deficits are apparent early in neurodevelopment, several years before the onset of psychosis (Cannon et al. 2006; Giuliano et al. 2012; Fusar-Poli et al. 2012a; Müller et al. 2013; Bora et al. 2014). Birth cohort and conscript studies report strong associations between poor performance on cognitive batteries and increased risk of later schizophrenia (MacCabe, 2008; MacCabe et al. 2008). Moreover, a systematic review and meta-analysis confirmed the presence of a premorbid IQ deficit of around 0.5 S.D. among young people who will later develop schizophrenia (Woodberry et al. 2008). By contrast, premorbid deficits seem to be absent, or even reversed, in bipolar disorder (Koenen et al. 2009; MacCabe et al. 2010).

Evidence supporting cognitive deterioration in schizophrenia is often based on indirect cross-sectional comparisons among individuals at different symptomatic phases, e.g. chronic schizophrenia, first episode, or at risk for psychosis (Bora \& Murray, 2013). Such observations of considerably less severe cognitive deficits in at-risk individuals than in first-episode or schizophrenia samples suggests a continuous decline potentially related to neurobiological changes. However, persons at risk may display fewer deficits either because they are 'earlier' along the continuum for psychosis or simply because of methodological problems, such as heterogeneous inclusion criteria (basic symptoms, high-risk, ultra-high risk) or moderate transition rates in at-risk psychosis samples (Ruhrmann et al. 2010; Simon \& Umbricht, 2010; Yung et al. 2010; Keshavan et al. 2011; Fusar-Poli et al. 2014). Furthermore, research related to the course of cognition after a first episode of psychosis is inconsistent (Kahn \& Keefe, 2013). Some have reported that cognitive ability remains stable or even improves by the time of the follow-up assessment (Becker et al. 2010) while others have noted deterioration in certain cognitive abilities (Brewer et al. 2006; Addington \& Barbato, 2012) or a relative cognitive decline compared to healthy control subjects (Hedman et al. 2013).

Investigations to identify clinical or neurocognitive markers in help-seeking individuals at risk for progression to bipolar disorder are still limited and inconsistent. A recent systematic review and meta-analysis from Trotta et al. (2015) comparing premorbid and/or post-onset global cognitive function between schizophrenia and bipolar disorder found that compared to healthy controls, schizophrenic patients showed a significant premorbid cognitive impairment and a large post-onset impairment. The bipolar disorder group exhibited only small significant deficits in premorbid intellectual function when this was assessed retrospectively but not prospectively, and a moderate cognitive impairment after onset. Results from an earlier prospective birth cohort study showed that, early in the developmental course of schizophrenia but not bipolar disorder, impairments can arise in tasks that involve psychomotor speed as well as attentional and executive abilities (Cannon et al. 2006). The conclusion has been that these impairments may be specific to schizophrenia-related rather than affective-disorder outcomes. Other deficits in certain neurocognitive domains, such as verbal memory and executive functioning, are also potential predictors of bipolar disorders Olvet et al. (2013). Thus, at-risk criteria for bipolar disorder are still in an early stage of development (Bechdolf et al. 2012). Because the presence of hypomanic symptoms in adolescence is strongly predictive of later bipolar disorders, Angst et al. (2005) have hypothesized that applying an instrument for self-assessment of those symptoms might increase the detection of such disorders.

Our study objective was to analyse the course of cognition and psychopathological symptoms in help-seeking individuals who initially met ultra-high-risk (Yung \& McGorry, 1996) and/or basic symptom criteria (Huber, 1966; Klosterkotter et al. 2001), defined as being at high risk for schizophrenic psychosis (HRSchiz) at the time of the baseline examination (reported in Metzler et al. 2014). These subjects were compared with help-seeking individuals who met only the risk criteria for affective 
psychosis (high-risk bipolar; HRBip). Individuals at risk of psychosis who did not convert were then compared with the group of individuals actually converting to psychosis during the follow-up period.

The following hypotheses were evaluated: (1) based on the assumption that different neuroregressive processes, such as excessive pruning or inflammation starting in adolescence and early adulthood, are the neurobiological substrate for the cognitive deterioration in schizophrenia (Insel, 2010; Bora \& Murray, 2013) a decline in cognitive function with progression over time in prodromal individuals could be assumed; (2) during baseline testing, individuals converting to psychosis already exhibit a lower level of cognitive performance compared with nonconverters; and (3) individuals at risk for affective psychosis show a less severe decline than individuals at risk for schizophrenic psychosis.

\section{Method}

\section{Subjects}

Individuals from the canton of Zurich, Switzerland, were recruited within the context of a study on early recognition of psychosis (ZInEP; in German: Zürcher Impulsprogramm zur nachhaltigen Entwicklung der Psychiatrie; www.zinep.ch). Potential participants either had learned about this study from a project website, flyers, or newspaper advertisements, or were referred to our staff by general practitioners, school psychologists, counselling services, psychiatrists, or psychologists. All subjects spoke proper German and had normal or corrected-to-normal vision, normal hearing, and normal motor limb function. Those aged $\geq 18$ years provided informed consent, while minors ( $<18$ years) gave assent in conjunction with parental informed consent. The study was approved by the canton's Ethics Committee and was performed in accordance with the Declaration of Helsinki.

Participants completed the neurocognitive assessment shortly after inclusion ( $\mathrm{t} 0$, baseline assessment) and, on average, 12.8 (s.D.=1.5) months later (t1, follow-up assessment). Subjects who had experienced a psychotic episode were tested when stabilized. In the follow-up assessment, the same neurocognitive tests were again performed. At baseline, neuropsychological data were available from 207 participants who fulfilled the inclusion criteria (see psychopathological assessment below) for high-risk (HR), ultra-high-risk (UHR) or at-risk bipolar (HRBip). Exclusion criteria for study participation were manifest schizophrenic, substance-induced, or organic psychosis; current substance or alcohol dependence; or an estimated verbal IQ $<80$. For comparison, 50 healthy persons, comprising our control group (CG), completed the neurocognitive assessment (for socio-demographic descriptions see Metzler et al. 2014). Their qualifying data suggested they were comparable in verbal intelligence, level of education and gender to persons in the other groups. Controls were screened with the Mini International Neuropsychiatric Interview (MINI; Sheehan et al. 1998) based on DSM-IV criteria to exclude persons with any past or present psychiatric disorder. Moreover, control subjects with a neurological or somatic disorder that might bias their cognition were excluded from the study. None of the controls were using psychotropic medication or illicit drugs.

At follow-up, complete psychopathological and neurocognitive assessments were retrieved from 86 participants. In total, $34 \%$ of the individuals meeting risk criteria were receiving psychotropic medication at baseline and $47 \%$ were receiving at least one medication at follow-up. These medications included atypical antipsychotic medications $(19 \%$ at baseline, $32 \%$ at follow-up), mood stabilizers (1\%, $1 \%)$, and antidepressive medication $(19 \%, 25 \%)$. Demographic data for individuals in the follow-up analysis $(N=86)$ are given in Table 1. Due to project-specific issues a followup assessment of the CG could not be performed.

\section{Psychopathological assessment}

To qualify for inclusion, participants were required to fulfil at least one of the following criteria at the baseline examination.

(1) HR: high-risk status for psychosis, as assessed by the Schizophrenia Proneness Interview, SPI-A (Adult version) or SPI-CY (Children-Youth version) (Schultze-Lutter et al. 2007; Schultze-Lutter \& Koch, 2009), having at least one cognitiveperceptive basic symptom or at least two cognitive disturbances, and not meeting any of the UHR inclusion criteria listed below.

(2) UHR: ultra-high-risk status for psychosis, as rated by the Structured Interview for Prodromal Syndromes (SIPS; Miller et al. 2003), having at least one attenuated psychotic symptom, or at least one brief limited intermittent psychotic symptom, or a state-trait criterion [reduction in global assessment of functioning (GAF; Endicott et al. 1976) of $>30 \%$ in the past year, plus either a schizotypal personality disorder or a first-degree relative with psychosis].

(3) HRBip: high risk for bipolar disorder, as defined by a score either $\geq 14$ on the Hypomania Checklist (HCL), a self-report measure of life-time hypomanic symptoms (Angst et al. 2005), or a score $\geq 12$ on the Hamilton Depression Scale (HAMD; Schutte \& Malouff, 1995); and not meeting any of the at-risk psychosis inclusion criteria listed above. 
Table 1. Demographic and clinical characteristics

\begin{tabular}{|c|c|c|c|c|}
\hline & HRSchiz & HRBip & CONV & Test statistics \\
\hline$N^{\mathrm{a}}$ & 60 & 10 & 12 & \\
\hline Age at baseline (years \pm S.D.) & $20.8( \pm 6.1)$ & $21.0( \pm 5)$ & $19.1( \pm 4.8)$ & $F=0.42, p=0.65$ \\
\hline Education (years \pm S.D.) & $10.3( \pm 3.1)$ & $11.6( \pm 3.7)$ & $10.0( \pm 2.1)$ & $F=0.73, p=0.48$ \\
\hline Gender (F:M) & $27: 33$ & $4: 6$ & $4: 8$ & $\chi^{2}=0.26, p=0.06$ \\
\hline Pre-morbid verbal IQ (mean \pm s.D.) & $105.0( \pm 12.0)$ & $110.7( \pm 12.0)$ & $94.8( \pm 7.4)$ & $F=4.50, p=0.006$ \\
\hline \multicolumn{5}{|l|}{ Medication $(\text { mean } \pm \text { S.D. })^{\mathrm{b}}$} \\
\hline Baseline & $13.5( \pm 41.0)$ & $5.7( \pm 18.0)$ & $98.4( \pm 170.0)$ & $F=7.16, p=0.001$ \\
\hline Follow-up & $34.2( \pm 82.0)$ & 0.0 & $302.2( \pm 282.0)$ & $F=23.94, p<0.001$ \\
\hline \multicolumn{5}{|l|}{ GAF (mean \pm S.D.) } \\
\hline Baseline & $55.9( \pm 13.9)$ & $66.5( \pm 10.9)$ & $52.2( \pm 14.0)$ & $F_{2,77}=3.28, p=0.05$ \\
\hline Follow-up & $66.0( \pm 13.8)$ & $74.4( \pm 16.2)$ & $54.7( \pm 20.2)$ & $F_{2,77}=4.77, p=0.01$ \\
\hline \multicolumn{5}{|c|}{ PANSS (mean \pm s.D.), positive symptom score } \\
\hline Baseline & $13.1( \pm 3.8)$ & $8.8( \pm 0.9)$ & $16.5( \pm 4.6)$ & $F_{2,77}=10.77, p<0.001$ \\
\hline Follow-up & $10.6( \pm 3.3)$ & $8.1( \pm 1.3)$ & $15.5( \pm 7.0)$ & $F_{2,77}=11.31, p<0.001$ \\
\hline \multicolumn{5}{|c|}{ PANSS (mean \pm S.D.), negative symptom score } \\
\hline Baseline & $13.8( \pm 5.7)$ & $11.5( \pm 4.4)$ & $20.2( \pm 5.7)$ & $F_{2,77}=7.97, p=0.001$ \\
\hline Follow-up & $11.8( \pm 4.6)$ & $10.1( \pm 4.5)$ & $22.1( \pm 6.6)$ & $F_{2,77}=18.78, p<0.001$ \\
\hline \multicolumn{5}{|c|}{ PANSS (mean \pm S.D.), general symptom score } \\
\hline Baseline & $31.2( \pm 7.5)$ & $26.4( \pm 3.6)$ & $38.7( \pm 9.2)$ & $F_{2,77}=7.74, p=0.001$ \\
\hline Follow-up & $25.4( \pm 5.7)$ & $21.8( \pm 3.6)$ & $37.1( \pm 11.6)$ & $F_{2,77}=16.52, p<0.001$ \\
\hline \multicolumn{5}{|l|}{ HAMD (mean \pm S.D.) } \\
\hline Baseline & $13.9( \pm 7.6)$ & $10.5( \pm 5.3)$ & $17.48( \pm 8.1)$ & $F_{2,77}=2.39, p=0.09$ \\
\hline Follow-up & $10.0( \pm 5.7)$ & $6.2( \pm 2.3)$ & $14.0( \pm 7.4)$ & $F_{2,77}=4.06, p=0.02$ \\
\hline
\end{tabular}

HRSchiz, High risk of schizophrenic psychosis; HRBip, high risk for bipolar disorder; CONV, Converter; GAF, Global Assessment of Functioning; PANSS, Positive and Negative Syndrome Scale; HAMD, Hamilton Depression Scale.

${ }^{\text {a }}$ Four converters to bipolar disorder are not displayed.

${ }^{\mathrm{b}}$ Chlorpromazine equivalents.

A transition to schizophrenia or bipolar disorder was diagnosed according to the International Classification of Psychiatric Symptoms, version 10 (ICD-10). Quantitative measures of psychopathology were further obtained as follows: psychotic symptoms (Positive and Negative Syndrome Scale, PANSS; Kay et al. 1987), current Axis I co-morbidity via MINI (Sheehan et al. 1998), general functioning per GAF, and satisfaction with their psychosocial domains of life (Manchester Short Assessment of Quality of Life, MANSA; Priebe et al. 1999). All assessments were conducted by trained, experienced psychiatrists or psychologists.

\section{Neurocognitive assessment}

A set of well-established neuropsychological tests was administered in a fixed order at baseline and follow-up (Table 2). The psychopathological and neurocognitive assessments were conducted by different investigators; hence neuropsychological testing and scoring were performed blind to diagnostic status. Verbal IQ was estimated with a German word recognition test (MWT-B; Lehrl, 1989) for adults or a test of receptive vocabulary for minors (PPVT; Dunn \& Dunn, 2003). Test scores were standardized by computing $z$ scores based on the performance of the CG. To reduce the amount of data and examine generalized and specific deficits across cognitive domains, scores were calculated for the independent domains of speed, attention, fluency, learning and memory, and working memory, as identified from the factor analysis described by Metzler et al. (2014).

\section{Statistical analysis}

The dropout analysis was performed on the 207 individuals who participated in the baseline assessment. All other analyses were performed with data obtained from the 86 persons who participated in both baseline and follow-up assessments. Subjects classified as HR or UHR at baseline who did not convert during the follow-up period were grouped together as at risk for schizophrenic psychosis (HRSchiz, $N=60$ ) and were compared with those in the HRBip $(N=10)$ and converter to schizophrenia $(\mathrm{CONV})(N=12)$ groups. The group of converters to bipolar disorder $(N=4)$ was considered too small and was excluded from analysis.

Demographic and clinical characteristics were compared between groups, using $\chi^{2}$ and Fisher's exact tests 
Table 2. Neurocognitive assessment

\begin{tabular}{|c|c|c|}
\hline Functional domain & Test & Variable \\
\hline Pre-morbid verbal IQ & $\begin{array}{l}\text { Vocabulary test: Mehrfachwahl-Wortschatz-Intelligenztest (MWT; Lehrl, } \\
\text { 1989); Peabody Picture Vocabulary Test (PPVT; Dunn \& Dunn, 2003) }\end{array}$ & Raw score correct \\
\hline Speed & $\begin{array}{l}\text { Trail-Making Test, Version A and B (TMT-A/B; Reitan \& Wolfson, 1985) } \\
\text { Digit Symbol Coding Test (DSCT; Subtest of Wechsler Adult Intelligence } \\
\text { Scale; German Version, Aster et al. 2006) }\end{array}$ & $\begin{array}{l}\text { Time to complete test } \\
\text { Number correct }\end{array}$ \\
\hline Attention & Continuous Performance Test (CPT-OX; Beck et al. 1956) & $\begin{array}{l}\text { Reaction time, number } \\
\text { of omissions }\end{array}$ \\
\hline Fluency & $\begin{array}{l}\text { Fluency Test, S-Words and Animals (RWT; Regensburger } \\
\text { Wortflüssigkeitstest; Aschenbrenner } \text { et al. 2000) }\end{array}$ & Number correct \\
\hline Learning/Memory & $\begin{array}{l}\text { Rey Auditory Verbal Learning Test (RAVLT; Helmstaedter et al. 2001), Rey } \\
\text { Visual Design and Learning Test (RVDLT; Spreen \& Strauss, 1991) }\end{array}$ & $\begin{array}{l}\mathrm{T} 1, \sum \mathrm{T} 1-\mathrm{T} 5 \text {, Delayed } \\
\text { recall, recognition }\end{array}$ \\
\hline Working memory & $\begin{array}{l}\text { Digit Span and Letter-Number Sequencing (DS and LNS; Subtests of Wechsler } \\
\text { Adult Intelligence Scale, German Version, Aster et al. 2006) }\end{array}$ & Number correct \\
\hline
\end{tabular}

for categorical variables or one-way analysis of variance (ANOVA) with a Bonferroni post-hoc test for continuous variables. Group comparisons of demographic and clinical variables were performed using Pearson's $\chi^{2}$ tests for categorical variables and one-way ANOVAs for continuous variables. Two-way repeated ANOVA was performed for all cognitive variables and cognitive domains as well as for the clinical variables with longitudinal data of interest (Medication, GAF, PANSS positive, PANSS negative, PANSS general symptom score). 'Group' (HRSchiz, HRBip, and CONV) was entered as the between-subjects factor while 'Time' (baseline and follow-up) was the repeated measure. Chlorpromazine equivalents (Andreasen et al. 2010) were added as a covariate in all models. Paired $t$ tests were used to compare baseline and follow-up data within each group.

One-way ANOVA with post-hoc LSD tests were used to compare the performance in the baseline assessment between the three groups (HRSchiz, HRBip, and CONV).

Bivariate correlations were conducted to examine the relationships of score changes (endpoint score minus baseline score) for both neurocognitive domains and clinical symptoms, with the alpha level adjusted using the Bonferroni procedure.

To analyse possible dropout features (sex, age, IQ, psychopathological and cognitive variables), subjects participating at both, baseline and follow-up assessment ('No drop-out', nodrop: $N=86$ ) were compared with subjects missing the follow-up assessment ['dropout', drop: $N=121(207-86)]$. All analyses were done with SPSS v. 20.0 (SPSS Inc., USA).

\section{Results}

\section{Demographic and clinical characteristics}

Based on their demographic and clinical characteristics, the participants within all groups had comparable educational levels, ages, and gender (Table 1), but differed in their pre-morbid IQs and neuroleptic medications. That is, the HRSchiz and HRBip groups had comparable IQs while the CONV group scored significantly lower. Likewise, the amount of neuroleptic medications utilized was comparable between HRSchiz and HRBip but significantly higher for CONV. At baseline, the three groups were not yet significantly different in their GAF total scores, but they were at follow-up. The CONV group displayed a significant lower GAF score than HRSchiz and HRBip. By 1 year after completing the initial assessment, 15 of the 177 HRSchiz subjects $(8.4 \%)$ had converted to schizophrenic psychosis. Considering only HRSchiz subjects with follow-up neuropsychological testing, the transition rate within 1 year is $16 \%$, as 12 of the 76 HRSchiz subjects had converted to schizophrenic psychosis.

\section{Psychopathological assessments}

Repeated-measures analyses were used to examine changes in psychopathological scores when Time and Time $\times$ Group interactions were considered. Significant effects for Group were found for PANSS positive, negative and general symptom score as well as for the GAF score. A significant main effect for Time was found for the PANSS positive symptom score $\left(F_{1,77}=\right.$ $4.84, p=0.03)$, PANSS general symptoms $\left(F={ }_{1,77}=8.45\right.$, $p=0.005)$, and $\operatorname{GAF}\left(F_{1,77}=7.48, p=0.008\right)$. For the negative symptom score, no significant Time or Time $\times$ Group interaction was identified (all $p>0.15$ ). Post-hoc analysis revealed that, during follow-up assessment, all groups showed improvements in positive symptomatology, but only the improvement by the HRSchiz group reached a statistically significant threshold ( $t=$ 4.92, $p=0.001)$. Whereas HRSchiz and HRBip improved in negative symptom scores $(t=2.40, p=0.02)$, CONV 


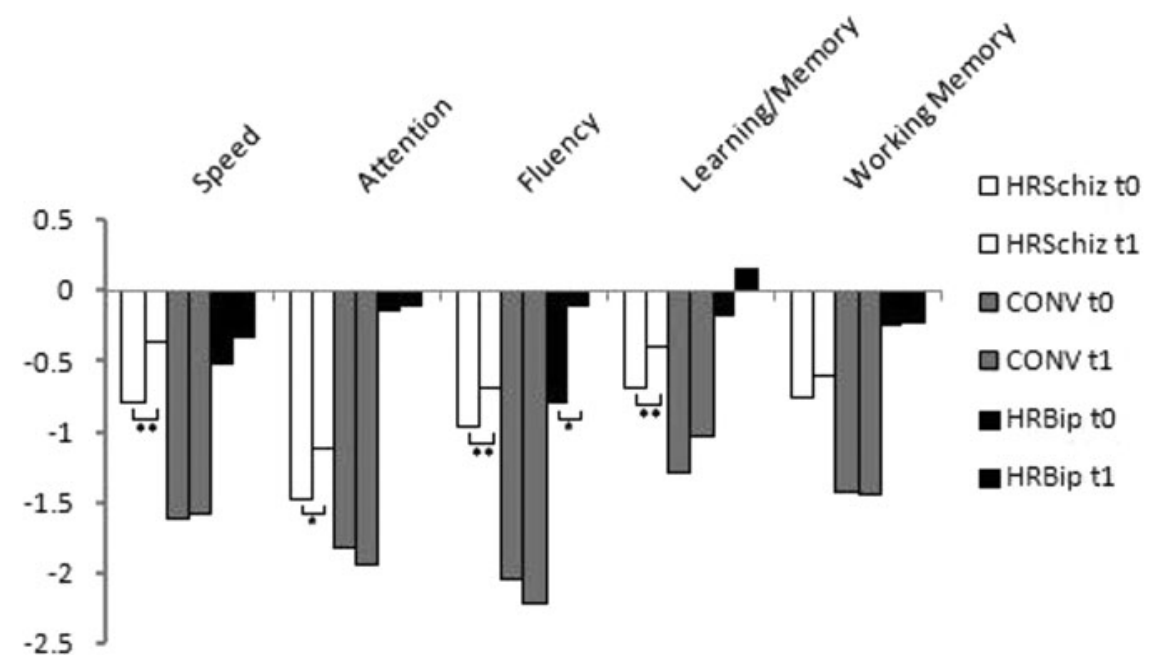

Fig. 1. Mean $z$ scores for high risk of schizophrenic psychosis (HRSchiz), converter (CONV), and high risk for bipolar disorder (HRBip) groups at baseline (t0) and follow-up (t1).

displayed more negative symptoms at follow-up. The general symptoms of CONV remained unchanged $(t=0.03, p=0.97)$ while HRSchiz $(t=5.20, p=0.001)$ and HRBip $(t=3.24, p=0.01)$ significantly improved. The GAF scores for both HRSchiz and HRBip were significantly improved $(t=-4.44, p=0.001$, and $t=-2.61, p=$ 0.02 , respectively), while that of CONV remained unchanged $(t=-0.48, p=0.63)$.

\section{Neurocognitive domains}

The neuropsychological profiles for the three clinical groups at baseline and follow-up are displayed in Fig. 1. Repeated-measures analyses were used to examine Group, Time, and Time $\times$ Group interactions. Significant effects for Group were found for the domains of speed, learning/memory, working memory, and fluency. Effects for Time were found for the domains of learning/memory and fluency, while a significant Time $\times$ Group interaction effect was noted for the fluency domain (Table 3). Post-hoc analysis revealed that, in the speed domain, HRSchiz showed improvement $(t=5.33, p=0.0001)$ while the HRBip and CONV groups remained stable. In the attention domain, HRSchiz showed a slight improvement over time $(t=-2.07, p=0.04)$, while the HRBip $(t=-0.42$, $p=0.67)$ and CONV groups had equal and consistent performances $(t=1.32, p=0.22)$. In the fluency domain, the HRSchiz $(t=-2.92, p=0.005)$, and HRBip $(t=-2.37, p=0.04)$ groups improved significantly over time, while the CONV group remained stable $(t=0.61, p=0.55)$. In the learning/memory domain, HRSchiz improved over time $(t=-3.13, p=0.003)$, while those improvements were not statistically significant in either the HRBip or CONV groups (all $p>0.05$ ).
In the working memory domain, no significant improvement was noted for any group (all $p>0.05$ ).

At baseline, the level of performance differed in the domains of speed $(F=4.30, \mathrm{df}=2, p=0.04)$, attention $(F=3.18, \quad \mathrm{df}=2, \quad p=0.04)$, learning/memory $(F=4.19$, $\mathrm{df}=2, p=0.01)$, working memory $(F=5.77, \mathrm{df}=2, p=$ $0.005)$, and fluency $(F=7.68, \mathrm{df}=2, p=0.001)$. Post-hoc analyses revealed that CONV performed at a significantly lower level than HRSchiz and HRBip in the domains of speed $(p=0.04)$, learning/memory $(p=0.03)$, working memory $(p=0.01)$, and fluency $(p=0.002)$.

Bivariate correlations between neurocognitive and clinical change scores across all groups revealed a negative association of the fluency domain with the PANSS positive symptoms scale $(r=0.306, p=0.006)$. The results of other comparisons did not survive the Bonferroni correction.

With regard to our analysis of dropout features, a $\chi^{2}$ test showed that the genders were equally distributed in the nodrop and drop groups $\left(\chi^{2}=1.71, \mathrm{df}=1, p=0.19\right)$. No significant differences were found between those groups in terms of mean age at intake and mean premorbid IQ $(t=1.27, \mathrm{df}=205, p=0.20$, and $t=-1.32, \mathrm{df}=205, p=0.18$, respectively). For the baseline assessment, none of the other psychopathological features (GAF score, HAMD, HCL, MANSA, PANSS) or cognitive domains differed significantly between nodrop and drop (all $p>0.05$ ).

\section{Discussion}

In this study, the range of neurocognitive performance was examined in a sample of individuals at risk for schizophrenic or affective psychoses, and subjects converting to psychosis during the follow-up period. Our findings suggested that first, non-converting individuals at risk for schizophrenic psychosis and 
Table 3. Domain scores (z scores) and test scores (raw score) for the three clinical groups at baseline and follow-up

\begin{tabular}{|c|c|c|c|c|c|c|c|c|c|c|c|c|c|c|}
\hline \multirow[b]{3}{*}{ Domain } & \multicolumn{6}{|c|}{ Baseline } & \multicolumn{8}{|c|}{ Follow-up } \\
\hline & \multicolumn{2}{|c|}{ HRSchiz } & \multicolumn{2}{|l|}{ CONV } & \multicolumn{2}{|l|}{ HRBip } & \multicolumn{2}{|c|}{ HRSchiz } & \multicolumn{2}{|l|}{$\mathrm{CONV}$} & \multicolumn{2}{|l|}{ HRBip } & \multicolumn{2}{|l|}{ Test statistics } \\
\hline & Mean & S.D. & Mean & S.D. & Mean & S.D. & Mean & S.D. & Mean & S.D. & Mean & S.D. & Time $(p)$ & Time $\mathrm{x}$ group $(p)$ \\
\hline Speed & -0.79 & 1.02 & -1.61 & 1.60 & -0.67 & 0.99 & -0.39 & 0.95 & -1.58 & 1.38 & -0.34 & 0.84 & $F_{1,79}=3.70(0.05)$ & $F_{2,79}=1.63(0.20)$ \\
\hline TMT_A & 26.85 & 7.00 & 30.47 & 16.04 & 25.74 & 8.05 & 23.75 & 6.60 & 30.90 & 13.75 & 25.29 & 6.52 & $F_{1,79}=0.92(0.34)$ & $F_{2,79}=1.70(0.90)$ \\
\hline TMT_B & 61.01 & 19.94 & 67.53 & 17.81 & 52.61 & 15.75 & 53.80 & 17.45 & 63.77 & 19.62 & 53.98 & 22.55 & $F_{1,79}=1.70(0.20)$ & $F_{2,79}=0.83(0.44)$ \\
\hline $\mathrm{DSCT}$ & 73.04 & 14.58 & 57.00 & 14.98 & 73.22 & 12.04 & 77.69 & 14.77 & 56.73 & 10.01 & 81.56 & 10.60 & $F_{1,79}=4.29(0.04)^{*}$ & $F_{2,79}=1.48(0.24)$ \\
\hline Attention & -1.47 & 2.65 & -1.83 & 2.60 & -0.15 & 0.69 & -1.11 & 2.46 & -1.94 & 1.66 & -0.12 & 0.98 & $F_{1,79}=0.34(0.56)$ & $F_{2,79}=1.14(0.32)$ \\
\hline CPT_RT & 478.80 & 117.90 & 528.80 & 89.90 & 450.10 & 74.50 & 467.25 & 118.80 & 500.92 & 101.50 & 434.00 & 66.80 & $F_{1,79}=1.26(0.26)$ & $F_{2,79}=0.00(0.99)$ \\
\hline CPT_Omis & 2.16 & 4.09 & 1.90 & 4.33 & 0.10 & 0.31 & 2.04 & 3.93 & 4.50 & 5.70 & 0.80 & 0.91 & $F_{1,79}=2.89(0.09)$ & $F_{2,79}=1.86(0.16)$ \\
\hline Learning/memory & -0.69 & 0.88 & -1.30 & 0.90 & -1.90 & 1.03 & -0.39 & 0.98 & -1.05 & 1.01 & 0.16 & 0.65 & $F_{1,79}=7.20(0.009)^{* *}$ & $F_{2,79}=0.06(0.94)$ \\
\hline RAVLT_T1 & 7.51 & 2.00 & 6.73 & 0.90 & 9.00 & 2.50 & 8.17 & 2.30 & 7.58 & 2.90 & 9.30 & 2.20 & $F_{1,79}=6.85(0.01)^{*}$ & $F_{2,79}=0.75(0.47)$ \\
\hline $\mathrm{RAVLT}_{-}^{-} \Sigma \mathrm{T} 1-5$ & 55.38 & 9.20 & 49.60 & 6.80 & 61.50 & 11.10 & 57.17 & 11.8 & 53.00 & 9.30 & 63.50 & 7.50 & $F_{1,79}=2.92(0.09)$ & $F_{2,79}=0.36(0.69)$ \\
\hline RAVLT_recall & 11.57 & 2.90 & 8.82 & 2.00 & 13.60 & 2.80 & 12.35 & 2.60 & 10.42 & 3.60 & 14.20 & 1.00 & $F_{1,79}=10.20(0.00)^{* *}$ & $F_{2,79}=0.63(0.20)$ \\
\hline RAVLT_recogn & 13.53 & 2.10 & 12.73 & 2.50 & 13.90 & 2.80 & 13.85 & 1.90 & 13.08 & 1.80 & 14.40 & 1.00 & $F_{1,79}=1.88(0.17)$ & $F_{2,79}=0.12(0.88)$ \\
\hline RVDLT_T1 & 5.32 & 2.20 & 5.17 & 1.90 & 5.60 & 2.30 & 6.25 & 2.30 & 5.42 & 2.20 & 7.00 & 2.20 & $F_{1,79}=5.49(0.02)^{*}$ & $F_{2,79}=0.62(0.53)$ \\
\hline RVDLT_$_{-} \Sigma \mathrm{T} 1-5$ & 50.80 & 10.20 & 46.58 & 13.10 & 53.60 & 9.90 & 53.52 & 10.50 & 44.58 & 10.80 & 59.70 & 7.30 & $F_{1,79}=3.01(0.08)$ & $F_{2,79}=2.36(0.10)$ \\
\hline RVDLT_recall & 12.58 & 2.30 & 11.00 & 3.10 & 13.40 & 2.00 & 12.98 & 2.20 & 10.92 & 3.80 & 13.80 & 1.60 & $F_{1,79}=0.51(0.47)$ & $F_{2,79}=0.24(0.78)$ \\
\hline RVDLT_recogn & 14.05 & 1.20 & 13.00 & 3.00 & 14.60 & 0.50 & 14.45 & 0.90 & 13.75 & 1.70 & 14.70 & 0.60 & $F_{1,79}=3.20(0.07)$ & $F_{2,79}=0.51(0.60)$ \\
\hline Working memory & -0.76 & 0.80 & -1.43 & 0.95 & -0.26 & 0.81 & -0.63 & 0.91 & -1.44 & 0.69 & -0.23 & 0.94 & $F_{1,79}=0.32(0.57)$ & $F_{2,79}=0.31(0.74)$ \\
\hline DS_total & 16.58 & 3.30 & 13.00 & 3.80 & 18.30 & 4.70 & 16.85 & 3.80 & 13.33 & 3.30 & 18.30 & 3.60 & $F_{1,79}=0.30(0.58)$ & $F_{2,79}=0.06(0.94)$ \\
\hline LNS & 10.77 & 2.40 & 9.36 & 3.10 & 12.80 & 3.10 & 11.08 & 2.50 & 9.60 & 2.50 & 11.25 & 1.90 & $F_{1,79}=0.04(0.82)$ & $F_{2,79}=2.00(0.14)$ \\
\hline Fluency & -0.96 & 0.90 & -2.04 & 0.65 & -0.80 & 1.26 & -0.71 & 1.00 & -2.21 & 1.04 & -0.12 & 0.72 & $F_{1,79}=5.11(0.02)^{*}$ & $F_{2,79}=3.36(0.04)^{*}$ \\
\hline RWT_S-Words & 12.13 & 3.80 & 8.64 & 2.70 & 12.90 & 4.20 & 13.47 & 4.30 & 9.42 & 4.50 & 17.10 & 3.90 & $F_{1,79}=16.25(0.00)^{* *}$ & $F_{2,79}=2.54(0.08)$ \\
\hline RWT_Animals & 21.13 & 4.50 & 16.73 & 2.90 & 22.10 & 6.70 & 21.40 & 4.60 & 14.50 & 4.70 & 22.80 & 4.70 & $F_{1,79}=0.17(0.67)$ & $F_{2,79}=1.14(0.33)$ \\
\hline
\end{tabular}

HRSchiz, High risk of schizophrenic psychosis; CONV, Converter; HRBip, high risk for bipolar disorder; TMT_A, Trail-Making Test, Version A; TMT_B, Trail-Making Test, Version B; DSCT, Digit Symbol Coding Test; CPT, Continuous Performance Test (_RT, reaction time; _Omis, number of omissions); RAVLT, Rey Auditory Verbal Leaning Test (T1, trial 1; $\Sigma T 1-5$, sum of trials 1-5; recogn, recognition); DS, Digit Span; LNS, Letter-Number Sequencing; RWT, Verbal Fluency Test (Regensburger Wortflüssigkeits-Test); s.D., standard deviation.

A repeated-measures ANOVA was performed for each measure, using group (HRSchiz, CONV, and HRBip) as between-subject factor and medication as covariate. 
converters to schizophrenia may show a diverging course as members in the former group improved in all cognitive domains except working memory while performance by those in the latter group remained stable. Second, the group of individuals who were later identified as converters to schizophrenia was already displaying a significantly lower level of general performance at the baseline assessment compared to the other two groups. Third, preliminarily, the performance by HRBip individuals began at a higher level than either HRSchiz or CONV participants, and showed stable or improved performance from baseline to follow-up. Across all groups, a reduction of positive symptoms was strongly associated with improvements in the fluency domain. In addition, it is important to emphasize that methodological challenges, such as the relatively short follow-up period or the small size of HRBip group limit our interpretations.

In contrast with the assumption of a progressive deteriorating path to psychosis, our sample of subjects at risk for psychosis did not show a significant decline in functioning but rather improvements that reached a statistical threshold in the domains of speed, attention, fluency, and learning/memory. Scores within the working memory domain remained stable for all three clinical groups. In subjects at risk for psychosis who did not convert during the follow-up period, improvements were observed over time in multiple cognitive domains, specifically in processing speed, verbal and visual learning, and memory. This has also been reported previously (Keefe et al. 2006; Becker et al. 2010; Barbato et al. 2013; Bora \& Murray, 2013). One might explain these improvements as a result of practice or placebo effects, such as increased motivation or decreased anxiety, upon being exposed to the same test a second time (Goldberg et al. 2010). In the learning and memory domain persons from all groups demonstrated improvements during the follow-up assessment, although this change was not statistically significant in the CONV group. Most likely in this domain, a paradigm, as well as content-specific, practice effect had occurred, i.e. familiarity with testing instructions/demands or explicit learning of the same words on a list. Likewise, an investigation by Crespo-Facorro et al. (2009) found that healthy control subjects had pronounced improvements in their Rey Auditory Verbal Learning Test (Helmstaedter et al. 2001) and Visual Design and Learning Test (non-verbal memory) (Spreen \& Strauss, 1991) [effect sizes (ES) up to 0.97$]$ that contrasted with smaller improvements in tests of attention (ES up to 0.2). In addition to such practice effects, a reduction or stabilization in the severity of symptoms at follow-up may substantially contribute to cognitive improvements (Bora \& Murray, 2013). In our study, the observed association between diminished positive symptoms and improvement in fluency tasks across all groups may support this proposition.

By contrast, CONV individuals did not show any significant improvement in cognitive functioning from baseline to follow-up but only consistencies in performances over time. Similar findings have been reported before (Keefe et al. 2006; Wood et al. 2007; Bora \& Murray, 2013). It is debatable to what extent a practice effect can be abolished by an underlying progressive cognitive decline related to pathophysiological changes. It is also conceivable that those in the CONV group displayed the same level of performance because they were immune to practice effects. The neuronal systems relevant for practice and implicit learning may be specifically impaired in individuals converting to psychosis. Besides, Bowie et al. (2012) have noted that second-generation antipsychotic medications in UHR individuals are associated with relatively negative effects on cognition at follow-up when compared with UHR subjects who are either untreated or taking antidepressants. However, in our study, the effects were still observable after carefully controlling for neuroleptic medication.

Individuals classified as HRBip exhibited a higher performance than the HRSchiz group. In line with that, earlier studies found that premorbid deficits seem to be absent, or even reversed, in bipolar disorder. This was shown in two longitudinal studies where individuals with better cognitive functioning in childhood or adolescence had an increased risk for later bipolar disorder (Koenen et al. 2009; MacCabe et al. 2010). However, the small size of the HRBip group restricts the extent to which our finding can be generalized. In addition, efforts to create diagnostic tools for early detection of bipolar disorder have only recently begun. This study applied recommended cutoff scores in self-assessment instruments like HCL-32 as diagnostic criteria (Angst et al. 2005). A next essential step would be to critically verify the validity and sensitivity of our approach and to compare it with the meanwhile available scale for early recognition of bipolar disorder (Correll et al. 2014).

Cognitive dysfunction has been regarded as a possible latent marker, or endophenotype, of genetic risk for schizophrenia (e.g. Heinrichs \& Zakzanis, 1998; Cosway et al. 2000). According to the neurodevelopmental model, cognitive deficits are already evident before the onset of psychosis. During baseline testing, our sample group of 'true' at-risk individuals with later conversion was exhibiting significantly lower performances on the domains of processing speed, fluency, learning/memory, and working memory, as well as a lower estimated pre-morbid IQ. Thus, our results may confirm the assumption that 
neurocognitive deficits are present prior to the development of psychosis (Cannon et al. 2006; Giuliano et al. 2012; Fusar-Poli et al. 2012a; Müller et al. 2013; Bora et al. 2014).

The findings regarding improvement in cognitive function by individuals at risk of psychosis tend to contradict the idea of a progressive decline in schizophrenia. It is questionable whether there is a continuum that defines these reportedly smaller but distinctly reduced performances by at-risk, but nonconverting individuals (Hambrecht et al. 2002; Brewer et al. 2005; Keefe et al. 2006; Niendam et al. 2006; Pukrop et al. 2006) and the intermediate deficits in 'true' positive individuals. The at-risk psychosis state is characterized by a marked impairment in psychosocial functioning (Velthorst et al. 2010), many co-morbidities (Yung et al. 2008), and multiple mental and functional deficits (Ruhrmann et al. 2010). Furthermore, a meta-analysis has revealed a modest effect toward reduced transition risks in the most recently published studies (Fusar-Poli et al. 2012b). Accordingly, the transition rate apparently decreases to $10-18 \%$ within 1 year (Yung \& Nelson, 2013); our results fell within this range. This means that, for a substantial proportion of the subjects initially labelled as at-risk, their conversion to psychosis may never happen. Likewise, better performances by the at-risk group than the converter group may hypothetically be a result of a subset of 'false positives' within the sample (Bora \& Murray, 2013; Zipursky et al. 2013). From a critical view, the cognitive deficits observed in at-risk compared to healthy individuals at baseline may reflect low psychosocial functioning in general rather than a compelling degradation associated with the path to manifestation of a disorder. It should be noted that our study plan did not involve any therapeutic intervention. One part of the participants in our study was treated by their resident psychiatrists and psychologist in the sense of a treatment as usual. Another part of the participants was not enrolled in any therapeutic offers. For our study we documented only the number and type of therapeutic contacts ant the received medication. However, regardless of treatment, non-converting subjects improved in positive and negative symptomatology.

Above all, the declining transition rate in subjects at risk for psychosis is a controversial issue, especially because a potential unnecessary diagnosis might give rise to unintended consequences such as stigma and discrimination (Yung et al. 2010). In particular, selflabelling and perceived public stigma can be related to heightened stress through stigma-associated cognitions that delicately reduce the well-being of young individuals diagnosed as at-risk (Rüsch et al. 2014). Therefore, more research is urgently needed concerning the possible side-effects of identifying a person as being 'at-risk of psychosis' (Yung et al. 2012).

The results of this study should be considered in the context of several limitations. The CONV and HRBip groups were relatively small, therefore the statistical power may be limited. The study project enabled only a relatively short follow-up period and it cannot be excluded, in fact, that a longer follow-up duration would have provided on the one hand more transitions, and on the other, evidence for a progressive cognitive decline instead of stability in the converter group. The duration of the follow-up would have been needed to extend for several years to clarify if the improvements represent a complete remission of symptoms, how long the improvements will continue, and to be sure that none of the individuals is falsely diagnosed, which is quite challenging to realize. Additionally, due to project-specific issues a follow-up assessment of the healthy CG, which would have provided further insights, was not performed. Further, there was a loss of $59 \%$ of individuals missing the 1-year follow-up assessment. A drop-out analysis found no differences in demographic and clinical baseline variables between subjects participating (nodrop) and not participating (drop) at the follow-up assessment. However, it cannot be excluded that with a smaller drop-out rate the study's results would be modified. However, our study benefited from the relatively large group of HRSchiz subjects in a longitudinal design, and the fact that we could control for confounding variables.

In summary, the at-risk psychosis sample comprised a heterogeneous group of individuals who performed at a lower level on neurocognitive tests when compared with healthy individuals. The neurocognitive performance in HRSchiz and HRBip improved over the duration of the follow-up period, and remained stable in the CONV group. Generally, in the helpseeking individuals, a substantial degree of recovery and spontaneous remission of psychopathological symptoms was observed over the duration of the study. Further studies with longer follow-up periods are needed to clarify the continuing course of their psycho-social functioning and neurocognitive performance. Moreover, further research is needed to verify and advance the approaches to create diagnostic tools for early detection of bipolar disorder.

\section{Acknowledgements}

This work was supported by the Zürich Impulse Program for the Sustainable Development of Mental Health Services (www.zinep.ch). Beyond funding, this Foundation had no further role in the experimental design; collection, analysis, and interpretation of data; 
the writing of this report; or the decision to submit this paper for publication. We thank the ZInEP team and the participants for enrolling in this study.

\section{Declaration of Interest}

Professor Dr Walitza has received lecture honoraria from Janssen Cilag, AstraZeneca and Eli Lilly in the last 5 years. Her work was partially supported in the last 5 years by the Swiss National Science Foundation (SNF), Deutsche Forschungsgemeinschaft, EU FP7, HSM Hochspezialisierte Medizin of Kanton Zurich, Switzerland, BMBF Germany.

\section{References}

Addington J, Barbato M (2012). The role of cognitive functioning in the outcome of those at clinical high risk for developing psychosis. Epidemiology Psychiatric Science 21, 335-342.

Andreasen NC, Pressler M, Nopoulos P, Miller D, Ho BC (2010). Antipsychotic dose equivalents and dose-years: a standardized method for comparing exposure to different drugs. Biological Psychiatry 67, 255-262.

Angst J, Adolfsson R, Benazzi F, Gamma A, Hantouche E, Meyer TD, Skeppar P, Vieta E, Scott J (2005). The HCL-32: towards a self-assessment tool for hypomanic symptoms in outpatients. Journal of Affective Disorders 88, 217-233.

Aschenbrenner A, Tucha O, Lange K (2000). Regensburger Wortflüssigkeits-Test. Handanweisung. Hogrefe: Göttingen.

Aster M, Neubauer A, Horn R (2006). Wechsler Intelligenztest für Erwachsene (WIE): Deutschsprachige Bearbeitung und Adaptation des WAIS-III von David Wechsler. Harcourt Test Services: Frankfurt am Main.

Barbato M, Colijn MA, Keefe RS, Perkins DO, Woods SW, Hawkins KA, Christensen BK, Addington J (2013). The course of cognitive functioning over six months in individuals at clinical high risk for psychosis. Psychiatry Research 206, 195-199.

Bechdolf A, Ratheesh A, Wood SJ, Tecic T, Conus P, Nelson B, Cotton SM, Chanen AM, Amminger GP, Ruhrmann S, Schultze-Lutter F, Klosterkotter J, Fusar-Poli P, Yung AR, Berk M, McGorry PD (2012). Rationale and first results of developing at-risk (prodromal) criteria for bipolar disorder. Current Pharmaceutical Design 18, 358-375.

Beck LH, Bransome ED Jr., Mirsky AF, Rosvold HE, Sarason I (1956). A continuous performance test of brain damage. Journal of Consulting and Clinical Psychology 20, 343-350.

Becker HE, Nieman DH, Wiltink S, Dingemans PM, van de Fliert JR, Velthorst E, de Haan L, van Amelsvoort TA, Linszen DH (2010). Neurocognitive functioning before and after the first psychotic episode: does psychosis result in cognitive deterioration? Psychological Medicine 40, 1599-1606.

Bora E, Lin A, Wood SJ, Yung AR, McGorry PD, Pantelis C (2014). Cognitive deficits in youth with familial and clinical high risk to psychosis: a systematic review and meta-analysis. Acta Psychiatrica Scandinavica 130, 1-15.
Bora E, Murray RM (2013). Meta-analysis of cognitive deficits in ultra-high risk to psychosis and first-episode psychosis: do the cognitive deficits progress over, or after, the onset of psychosis? Schizophrenia Bulletin 40, 744-755.

Bowie CR, McLaughlin D, Carrion RE, Auther AM, Cornblatt BA (2012). Cognitive changes following antidepressant or antipsychotic treatment in adolescents at clinical risk for psychosis. Schizophrenia Research 137, 110-117.

Brewer WJ, Francey SM, Wood SJ, Jackson HJ, Pantelis C, Phillips LJ, Yung AR, Anderson VA, McGorry PD (2005). Memory impairments identified in people at ultra-high risk for psychosis who later develop first-episode psychosis. American Journal of Psychiatry 162, 71-78.

Brewer WJ, Wood SJ, Phillips LJ, Francey SM, Pantelis C, Yung AR, Cornblatt B, McGorry PD (2006). Generalized and specific cognitive performance in clinical high-risk cohorts: a review highlighting potential vulnerability markers for psychosis. Schizophrenia Bulletin 32, 538-555.

Cannon M, Moffitt TE, Caspi A, Murray RM, Harrington H, Poulton R (2006). Neuropsychological performance at the age of 13 years and adult schizophreniform disorder: prospective birth cohort study. British Journal of Psychiatry 189, 463-464.

Cohen P, Cohen J (1984). The clinician's illusion. Archives of General Psychiatry 41, 1178-1182.

Correll CU, Olvet DM, Auther AM, Hauser M, Kishimoto T, Carrión RE, Snyder S, Cornblatt BA (2014). The Bipolar Prodrome Symptom Interview and Scale-Prospective (BPSS-P): description and validation in a psychiatric sample and healthy controls. Bipolar Disorder 16, 505-522.

Cosway R, Byrne M, Clafferty R, Hodges A, Grant E, Abukmeil SS, Lawrie SM, Miller P, Johnstone EC (2000). Neuropsychological change in young people at high risk for schizophrenia: results from the first two neuropsychological assessments of the Edinburgh High Risk Study.

Psychological Medicine 30, 1111-1121.

Crespo-Facorro B, Rodriguez-Sanchez JM, Perez-Iglesias R, Mata I, Ayesa R, Ramirez-Bonilla M, Martinez-Garcia O, Vazquez-Barquero JL (2009). Neurocognitive effectiveness of haloperidol, risperidone, and olanzapine in first-episode psychosis: a randomized, controlled 1-year follow-up comparison. Journal of Clinical Psychiatry 70, 717-729.

Dunn LM, Dunn L (2003). Peabody Picture Vocabulary Test: Deutschsprachige Fassung für Jugendliche und Erwachsene. Swets Test Services: Frankfurt am Main.

Endicott J, Spitzer RL, Fleiss JL, Cohen J (1976). The global assessment scale. A procedure for measuring overall severity of psychiatric disturbance. Archives of General Psychiatry 33, 766-771.

Fioravanti M, Carlone O, Vitale B, Cinti ME, Clare L (2005). A meta-analysis of cognitive deficits in adults with a diagnosis of schizophrenia. Neuropsychological Review 15, 73-95.

Fusar-Poli P, Bonoldi I, Yung AR, Borgwardt S, Kempton MJ, Valmaggia L, Barale F, Caverzasi E, McGuire P (2012a). Predicting psychosis: meta-analysis of transition outcomes in individuals at high clinical risk. Archives of General Psychiatry 69, 220-229. 
Fusar-Poli P, Deste G, Smieskova R, Barlati S, Yung AR, Howes $O$, Stieglitz RD, Vita A, McGuire P, Borgwardt $S$ (2012b). Cognitive functioning in prodromal psychosis: a meta-analysis. Archives of General Psychiatry 69, 562-571.

Fusar-Poli P, Yung AR, McGorry P, van Os J (2014). Lessons learned from the psychosis high-risk state: towards a general staging model of prodromal intervention. Psychological Medicine 44, 17-24.

Giuliano AJ, Li H, Mesholam-Gately RI, Sorenson SM, Woodberry KA, Seidman LJ (2012). Neurocognition in the psychosis risk syndrome: a quantitative and qualitative review. Current Pharmaceutical Design 18, 399-415.

Goldberg TE, Keefe RS, Goldman RS, Robinson DG, Harvey PD (2010). Circumstances under which practice does not make perfect: a review of the practice effect literature in schizophrenia and its relevance to clinical treatment studies. Neuropsychopharmacology 35, 1053-1062.

Hambrecht M, Lammertink M, Klosterkotter J, Matuschek E, Pukrop R (2002). Subjective and objective neuropsychological abnormalities in a psychosis prodrome clinic. British Journal of Psychiatry (Suppl.) 43, s30-s37.

Hedman AM, van Haren NE, van Baal CG, Kahn RS, Hulshoff Pol HE (2013). IQ change over time in schizophrenia and healthy individuals: a meta-analysis. Schizophrenia Research 146, 201-208.

Heinrichs RW, Zakzanis KK (1998). Neurocognitive deficit in schizophrenia: a quantitative review of the evidence. Neuropsychology 12, 426-445.

Helmstaedter C, Lendt M, Lux S (2001). Verbaler Lern- und Merkfähigkeitstest (VLMT). Hogrefe: Göttingen.

Huber G (1966). Reine Defektsyndrome und Basis-Stadien endogener Psychosen. Fortschritte der Neurologie - Psychiatrie 34, 409-426.

Insel TR (2010). Rethinking schizophrenia. Nature 468, 187-193.

Jablensky A (2007). Living in a Kraepelinian world: Kraepelin's impact on modern psychiatry. History of Psychiatry 18, 381-388.

Kahn RS, Keefe RS (2013). Schizophrenia is a cognitive illness: time for a change in focus. JAMA Psychiatry 70, 1107-1112.

Kay SR, Fiszbein A, Opler LA (1987). The positive and negative syndrome scale (PANSS) for schizophrenia. Schizophrenia Bulletin 13, 261-276.

Keefe RS, Perkins DO, Gu H, Zipursky RB, Christensen BK, Lieberman JA (2006). A longitudinal study of neurocognitive function in individuals at-risk for psychosis. Schizophrenia Research 88, 26-35.

Keshavan MS, DeLisi LE, Seidman LJ (2011). Early and broadly defined psychosis risk mental states. Schizophrenia Research 126, 1-10.

Klosterkotter J, Hellmich M, Steinmeyer EM, SchultzeLutter F (2001). Diagnosing schizophrenia in the initial prodromal phase. Archives of General Psychiatry 58, 158-164.

Koenen KC, Moffitt TE, Roberts AL, Martin LT, Kubzansky L, Harrington H, Poulton R, Caspi A (2009). Childhood IQ and adult mental disorders: a test of the cognitive reserve hypothesis. American Journal of Psychiatry 166, 50-57.

Lehrl S (1989). Mehrfachwahl-Wortschatz-Intelligenztest (MWT-B). Perimed: Erlangen.
MacCabe JH (2008). Population-based cohort studies on premorbid cognitive function in schizophrenia.

Epidemiologic Reviews 30, 77-83.

MacCabe JH, Lambe MP, Cnattingius S, Sham PC, David AS, Reichenberg A, Murray RM, Hultman CM (2010). Excellent school performance at age 16 and risk of adult bipolar disorder: national cohort study. British Journal of Psychiatry 196, 109-115.

MacCabe JH, Lambe MP, Cnattingius S, Torrång A, Björk C, Sham PC, David AS, Murray RM, Hultman CM (2008).

Scholastic achievement at age 16 and risk of schizophrenia and other psychoses: a national cohort study. Psychological Medicine 38, 1133-1140.

Metzler S, Dvorsky D, Wyss C, Müller M, Traber-Walker N, Walitza S, Theodoridou A, Rössler W, Heekeren K (2014) Neurocognitive profiles in help-seeking individuals: Comparison of risk for psychosis and bipolar disorder criteria. Psychological Medicine. Published online 17 June 2014. doi:10.1017/S0033291714001007.

Michie PT, Kent A, Stienstra R, Castine R, Johnston J, Dedman K, Wichmann H, Box J, Rock D, Rutherford E, Jablensky A (2000). Phenotypic markers as risk factors in schizophrenia: neurocognitive functions. Australian and New Zealand Journal of Psychiatry 34, 74-85.

Miller TJ, McGlashan TH, Rosen JL, Cadenhead K, Cannon T, Ventura J, McFarlane W, Perkins DO, Pearlson GD, Woods SW (2003). Prodromal assessment with the structured interview for prodromal syndromes and the scale of prodromal symptoms: predictive validity, interrater reliability, and training to reliability. Schizophrenia Bulletin 29, 703-715.

Müller M, Vetter S, Weiser M, Frey F, Ajdacic-Gross V, Stieglitz RD, Rossler W (2013). Precursors of cognitive impairments in psychotic disorders: a population-based study. Psychiatry Research 210, 329-337.

Niendam TA, Bearden CE, Johnson JK, McKinley M, Loewy R, O'Brien M, Nuechterlein KH, Green MF, Cannon TD (2006). Neurocognitive performance and functional disability in the psychosis prodrome. Schizophrenia Research 84, 100-111.

Olvet DM, Burdick KE, Cornblatt BA (2013). Assessing the potential to use neurocognition to predict who is at risk for developing bipolar disorder: a review of the literature. Cognitive Neuropsychiatry 18, 129-145.

Pantelis C, Velakoulis D, McGorry PD, Wood SJ, Suckling J, Phillips LJ, Yung AR, Bullmore ET, Brewer W, Soulsby B, Desmond P, McGuire PK (2003). Neuroanatomical abnormalities before and after onset of psychosis: a cross-sectional and longitudinal MRI comparison. Lancet 361, 281-288.

Priebe S, Huxley P, Knight S, Evans S (1999). Application and results of the Manchester Short Assessment of Quality of Life (MANSA). International Journal of Social Psychiatry 45, 7-12.

Pukrop R, Schultze-Lutter F, Ruhrmann S, Brockhaus-Dumke A, Tendolkar I, Bechdolf A, Matuschek E, Klosterkotter J (2006). Neurocognitive functioning in subjects at risk for a first episode of psychosis compared with first- and multiple-episode schizophrenia. 
Journal of Clinical and Experimental Neuropsychology 28, 1388-1407.

Reitan RM, Wolfson D (1985). The Halstead-Reitan Neuropsychological Test Battery: Therapy and Clinical Interpretation. Neuropsychological Press: Tucson.

Ruhrmann S, Schultze-Lutter F, Klosterkotter J (2010). Probably at-risk, but certainly ill-advocating the introduction of a psychosis spectrum disorder in DSM-V. Schizophrenia Research 120, 23-37.

Rüsch N, Corrigan PW, Heekeren K, Theodoridou A, Dvorsky D, Metzler S, Muller M, Walitza S, Rossler W (2014). Well-being among persons at risk of psychosis: the role of self-labeling, shame, and stigma stress. Psychiatric Services 65, 483-489.

Schultze-Lutter F, Addington J, Ruhrmann S, Klosterkotter J (2007). Schizophrenia Proneness Instrument, Adult Version (SPI-A). Giovanni Fioriti Editore: Rome.

Schultze-Lutter F, Koch E (2009). Schizophrenia Proneness Instrument, Child and Youth Version (SPI-CY). Giovanni Fioriti Editore: Rome.

Schutte N, Malouff J (1995). Sourcebook of Adult Assessment Strategies. Plenum Press: New York.

Sheehan DV, Lecrubier Y, Sheehan KH, Amorim P, Janavs J, Weiller E, Hergueta T, Baker R, Dunbar GC (1998). The Mini-International Neuropsychiatric Interview (M.I.N.I.): the development and validation of a structured diagnostic psychiatric interview for DSM-IV and ICD-10. Journal of Clinical Psychiatry 59 (Suppl 20), 22-33; quiz 34-57.

Shenton ME, Dickey CC, Frumin M, McCarley RW (2001). A review of MRI findings in schizophrenia. Schizophrenia Research 49, 1-52.

Simon AE, Umbricht D (2010). High remission rates from an initial ultra-high risk state for psychosis. Schizophrenia Research 116, 168-172.

Spreen O, Strauss E (1991). A Compendium of Neuropsychological Tests: Administration, Norms and Commentary. Oxford University Press: New York.

Stefanopoulou E, Manoharan A, Landau S, Geddes JR, Goodwin G, Frangou S (2009). Cognitive functioning in patients with affective disorders and schizophrenia: a meta-analysis. International Review of Psychiatry 21, 336-356.

Trotta A, Murray RM, MacCabe JH (2014). Do premorbid and post-onset cognitive functioning differ between schizophrenia and bipolar disorder? A Systematic Review and Meta-Analysis. Psychological Medicine 45, 381-394. van Os J, Kapur S (2009). Schizophrenia. Lancet 374, 635-645. Velthorst E, Nieman DH, Linszen D, Becker H, de Haan L, Dingemans PM, Birchwood M, Patterson P, Salokangas

RK, Heinimaa M, Heinz A, Juckel G, von Reventlow HG, French P, Stevens H, Schultze-Lutter F, Klosterkotter J, Ruhrmann S (2010). Disability in people clinically at high risk of psychosis. British Journal of Psychiatry 197, 278-284.

Wood SJ, Brewer WJ, Koutsouradis P, Phillips LJ, Francey SM, Proffitt TM, Yung AR, Jackson HJ, McGorry PD, Pantelis C (2007). Cognitive decline following psychosis onset: data from the PACE clinic. British Journal of Psychiatry (Suppl.) 51, s52-s57.

Woodberry KA, Giuliano AJ, Seidman LJ (2008). Premorbid IQ in schizophrenia: a meta-analytic review. American Journal of Psychiatry 165, 579-587.

Yung AR, McGorry PD (1996). The prodromal phase of first-episode psychosis: past and current conceptualizations. Schizophrenia Bulletin 22, 353-370.

Yung AR, Nelson B (2013). The ultra-high risk concept-a review. Canadian Journal of Psychiatry 58, 5-12.

Yung AR, Nelson B, Stanford C, Simmons MB, Cosgrave EM, Killackey E, Phillips LJ, Bechdolf A, Buckby J, McGorry PD (2008). Validation of 'prodromal' criteria to detect individuals at ultra high risk of psychosis: 2 year follow-up. Schizophrenia Research 105, 10-17.

Yung AR, Nelson B, Thompson AD, Wood SJ (2010). Should a 'Risk Syndrome for Psychosis' be included in the DSMV? Schizophrenia Research 120, 7-15.

Yung AR, Woods SW, Ruhrmann S, Addington J, Schultze-Lutter F, Cornblatt BA, Amminger GP, Bechdolf A, Birchwood M, Borgwardt S, Cannon TD, de Haan L, French P, Fusar-Poli P, Keshavan M, Klosterkotter J, Kwon JS, McGorry PD, McGuire P, Mizuno M, Morrison AP, Riecher-Rossler A, Salokangas RK, Seidman LJ, Suzuki M, Valmaggia L, van der Gaag M, Wood SJ, McGlashan TH (2012). Whither the attenuated psychosis syndrome? Schizophrenia Bulletin 38, 1130-1134.

Zipursky RB, Lambe EK, Kapur S, Mikulis DJ (1998). Cerebral gray matter volume deficits in first episode psychosis. Archives of General Psychiatry 55, 540-546.

Zipursky RB, Reilly T, Murray RM (2013). The myth of schizophrenia as a progressive brain disease. Schizophrenia Bulletin 39, 1363-1372. 